\title{
An anthropometric evaluation of the augmented breast: differences between cis-and transgender women and possible clinical implications
}

\author{
Floyd Wilhelmus Timmermans ${ }^{1,2,3} \cdot$ Sterre Elisabeth Mokken ${ }^{1,2,4} \mathbb{C}^{(1)} \cdot$ Brian Scheffers $^{1} \cdot$ Mark-Bram Bouman $^{1,2}$. \\ Margriet Mullender ${ }^{1,2,3,4} \cdot$ Tim van de Grift ${ }^{1,2,4}$
}

Received: 20 May 2021 / Accepted: 5 July 2021 / Published online: 21 July 2021

(C) The Author(s) 2021

\begin{abstract}
Background The morphometric results after breast augmentations are generally understood to be clinically different between trans(gender) and cis(gender) women. The objective of this study was to establish these morphometric differences between the augmented breasts of trans and cis women and their implications for preoperative planning and expectation management of trans women.

Methods A single-center, observational cross-sectional study was conducted. Three-dimensional images (VECTRA) of the chest were taken and used to measure preset morphometric parameters. Subsequently, several proportional morphometric outcome variables were calculated. We compared body, breast, and nipple dimensions and their interdependence between trans and cis women. The main outcome sets were (1) the relative dimensions of the chest, (2) the position of the breasts relative to the chest, (3) and the position of the nipple relative to the breast and nipple size.

Results A total of 22 transgender and 22 cisgender women were included. The results showed that the breasts of the trans women were positioned more cranial. Furthermore, the nipple-areola complexes (NAC) were significantly smaller and positioned relatively more latero-cranial on the breasts.

Conclusions Morphological characteristics of augmented breasts differ significantly between trans and cis women. The results of this study identified distinct differences between the augmented breasts of trans and cis women. Because of the apparent differences in results, surgical considerations, expectation management, and shared decision-making should play an even more pronounced role in breast augmentations in trans women.
\end{abstract}

Level of evidence: Level III, risk/prognostic study.

Keywords Transgender $\cdot$ Breast augmentation $\cdot$ Anthropometry $\cdot$ Mammoplasty

Sterre Elisabeth Mokken

1 Department of Plastic, Reconstructive and Hand Surgery, Amsterdam University Medical Center, location VUMC, De Boelelaan 1117, Amsterdam, The Netherlands

2 Center of Expertise on Gender Dysphoria, Amsterdam University Medical Center, location VUMC, Amsterdam, The Netherlands

3 Amsterdam Movement Sciences Research Institute, VU University Medical Center, Amsterdam, The Netherlands

4 Amsterdam Public Health Research Institute, VU University Medical Center, Amsterdam, The Netherlands

\section{Introduction}

The increasing public visibility and acceptance of transgender individuals in society are reflected in an exponential growth of requests for gender-affirming surgery [2, 31]. In trans(gender) women, achieving the physical appearance that matches one's experienced gender is generally considered crucial for successful affirmation of one's female gender identity. As a result, most trans women will undergo demasculinization and feminization through hormonal and surgical treatments [6]. Hormone therapy is known to increase fat deposition at the waist, and to a lesser extent, promote breast development for up to 5 years after therapy initiation $[10,12]$. Unfortunately, breast growth can remain limited to the effect of estrogen therapy alone and a majority of trans 
women will seek to undergo breast augmentation to achieve a gender-congruent chest $[11,18,19]$.

However, breast volume is not the only factor considered to determine chest femininity. At a glance, the feminine chest differs greatly from the masculine chest. The cisgender male chest is generally wider and has less breast tissue, smaller, more lateralized nipple-areola complexes (NAC), more prominent pectoral mass, and a shorter distance from the nipple to the inframammary fold $[1,4,5,15,27]$. These baseline differences are clinically understood to result in noticeable differences in outcome after breast augmentation in trans women. Some have accredited the resulting morphometric differences to these gender-specific chest configurations, while others have claimed that the telltale difference lays in nipple-areola positioning and nipple size $[6,18,20]$. Although research has acknowledged these clinically understood differences, no study to date has examined the exact morphological differences in surgical outcomes between cis and trans women after breast augmentation. Therefore, the objective of this study was to assess the results following gender-affirming breast augmentations in our center by establishing morphometric differences between the augmented breasts in trans and cis women and to test whether proclaimed differences are accurate. In conducting this study, we sought to compare body, breast, and nipple dimensions and their interdependence between trans and cis women. Furthermore, we attempted to translate these differences into suggestions on improving preoperative planning and expectation management of trans women.

\section{Material and methods}

\section{Participants}

This was a single-center, observational cross-sectional study. Cis and trans women that previously had undergone a breast augmentation were included in this study. Potential participants were approached by telephone and inclusion was on voluntary basis. All patients provided written informed consent and were approached indiscriminately. Exclusion criteria were ptosis grade III or IV, displaced implants due to capsular contraction (Baker III/IV), or an autologous breast reconstruction combined with prosthesis and/or having undergone additional surgery such as lipofilling of the cleavage. Trans women were diagnosed and treated according to the Standards of Care of the World Professional Association for Transgender Health [8]. Transgender participants were required to have been on estrogen therapy for at least 1 year before surgery and at least 1 year since the augmentation should have elapsed. The protocol was approved by the institutional review board of the Amsterdam UMC (2019.011) and was performed in accordance with the Declaration of Helsinki and guidelines for Good Clinical Practice.

\section{Study procedures}

Participants were invited to the outpatient clinic for morphometric measurements. A 3-D camera (VECTRA-camera software version 5.7.1. by Canfield Inc.) was used to capture 3-D images of the upper anterior chest. Participants were asked to stand upright with their arms at a 45-degree angle and hand palms faced anteriorly. The placement of preset and self-established landmarks (see "Outcomes") allowed for volumetric assessments and measurement of distances between landmarks, both in straight lines and following the surfaces, between landmarks in metric values $(\mathrm{cm} / \mathrm{mm})$ by the 3-D camera software. A measuring protocol on the exact locations of the landmarks was established a priori, and B.S. was trained to perform the measurements.

\section{Outcomes}

Demographic data was recorded on age, height, weight, duration of estrogen therapy before breast augmentation in trans women, augmented breast volume, implant size, the time between augmentation and 3-D imaging, implant shape, and implant pocket. The main outcome sets were (1) relative dimensions of the chest (i.e., sternal-notch-to-umbilicus to height ratio), (2) position of the breasts relative to the chest (i.e., intermammary distance and breast width to chest width ratio), (3) and the position of the nipple relative to the chest, breast, and nipple size (i.e., nippleto-inframammary borders to chest width ratio). The measured anatomic distances are presented in Table 1 and Figs. 2 and 3. To correct for the inherently different body dimensions between cis and trans women, we sought to not only provide absolute measurements but to correct for these body dimensions as well by establishing ratios with chest width (horizontal vector) and upper body length (vertical vector). The length of the upper body and thorax width were defined and established respectively by measuring the straight distances between sternal-notch- (SN$\mathrm{U}$ ) and the anterior-axillar-fold to anterior-axillar-fold (AUXAUX). Subsequently, upper body length, chest width and, if appropriate, breast width (BW) were used as references to ratio and normalize the anatomic dimensions of the breast and nipples between the two groups.

\section{Statistical analysis}

IBM SPSS software Version 26.0 for Windows (IBM Corp., Armonk, N.Y.) was used for statistical analyses. Descriptive statistics were used to establish patient demographics. Gaussian continuous variables were presented as means with standard deviations and nonGaussian continuous variables were presented as medians 
Table 1 3-D-assisted anatomic measurements and their abbreviations
Abbreviation

$\begin{array}{ll}\text { Chest measurements } & \\ \text { - Chest Width (Axillary fold to axillary fold (straight line)) } & \text { AUX-AUX } \\ \text { - Upper body length (Sternal notch to umbilicus (straight line)) } & \text { SN-U } \\ \text { Breast measurements } & \text { BW } \\ \text { - Breast width (across body surface) } & \text { SN-IMF-L } \\ \text { - Sternal notch to the IMF level (straight line along the midline) } & \text { IMD } \\ \text { - Intermammary distance (straight line) } & \\ \text { Nipple measurements } & \text { AD } \\ \text { - Areolar horizontal diameter (straight line) } & \text { N-MIMF } \\ \text { - Nipple to medial IMF (across body surface) } & \text { N-LIMF } \\ \text { - Nipple to lateral IMF (across body surface) } & \text { N-AUX } \\ \text { - Nipple to anterior axillar fold (straight line) } & \text { NN } \\ \text { - Nipple to nipple (straight line) } & \text { N-IMF } \\ \text { - Nipple to IMF (across body surface) } & \end{array}$

with interquartile ranges. Statistical comparisons between the outcome measures were conducted using independent $t$-tests for continuous variables for Gaussian variables and the Mann-Whitney $U$ test for non-Gaussian variables. A $p$-value of $<0.05$ was considered statistically significant. When applicable, measurements are provided as means of bilateral measurements.

\section{Results}

\section{Demographics}

A total of 44 participants were included in this study; 22 transgender and 22 cisgender women. Demographic and implant-related data are presented in Table 2. Cis women were significantly older at the time of imaging $(p=0.01)$, whereas the trans women were significantly taller $(p<0.001)$ and heavier $(p<0.001)$. At the time of the breast augmentation, the trans women were on estrogen therapy for an average of 4.3 years (range 2.4-10.6 years). All implants were placed via an IMF incision. The implant size used in the trans women was also significantly larger than in the cis female group $(p<0.001)$. The difference in implant size did not result in a significant difference in breast size between the groups $(p=0.63)$. The median time between the augmentation and 3-D imaging for cis women was 9.0 years (IQR 5-11) and 2.0 (IQR 1.5-3.5) for trans women $(p=<0.001)$. The shape and location of implant placement were distributed fairly evenly. An onscale portrayal of the general result seen in trans women and cis women is shown in Fig. 1.
Table 2 Demographics and implant-related data

\begin{tabular}{lllc}
\hline & $\begin{array}{l}\text { Cis women } \\
(n=22)\end{array}$ & $\begin{array}{l}\text { Trans women } \\
(n=22)\end{array}$ & $P$-value \\
\hline Age (years) & $45.1 \pm 7.7$ & $36.1 \pm 12.3$ & 0.01 \\
Height (m) & $1.71 \pm 0.06$ & $1.80 \pm 0.04$ & $<0.001$ \\
Weight (kg) & $65.1 \pm 6.9$ & $76.7 \pm 13.9$ & $<0.001$ \\
BMI & $22.3 \pm 2.2$ & $23.5 \pm 3.3$ & 0.15 \\
Estrogen therapy in years at time of surgery (range) & N/A & $4.3(2.4-10.6)$ & N/A \\
Breast size (cc) & $552.95 \pm 158.3$ & $574.31 \pm 132.1$ & 0.63 \\
Implant size (cc) & $315.0 \pm 82.2$ & $399.8 \pm 88.6$ & $<0.001$ \\
Time since implantation & $9.0 \mathrm{IQR} 5-11$ & $2.0 \mathrm{IQR} 1.5-3.4$ & $<0.001^{*}$ \\
Implant shape & & & 0.75 \\
$\quad$ - Anatomic & $14(64 \%)$ & $15(68 \%)$ & \\
$\quad$ - Round & $8(36 \%)$ & $7(32 \%)$ & 0.46 \\
Implant pocket & & & \\
$\quad$ - Subglandular & $5(23 \%)$ & $3(14 \%)$ & $19(86 \%)$ \\
$\quad$ - Subpectoral & $17(77 \%)$ & & \\
\hline
\end{tabular}

*Mann-Whitney $U$ test 
Fig. 1 Portrayal the results in a trans woman (left) and a cis woman (right). Depiction is to scale

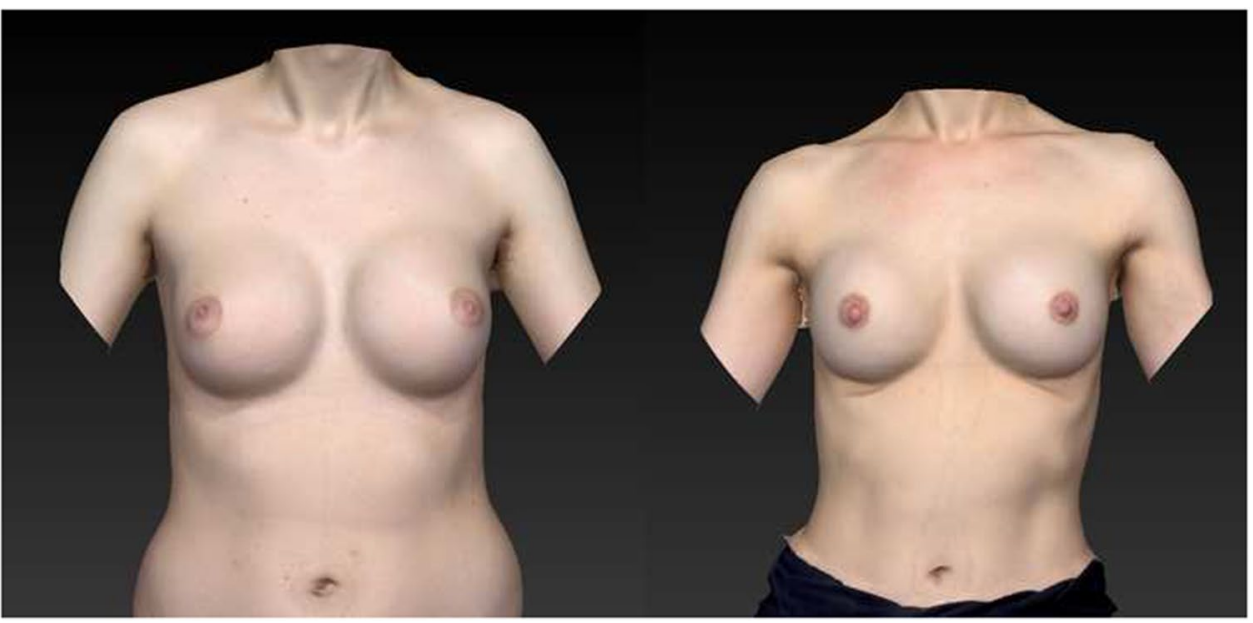

Table 3 Chest dimensions in absolute and relative values corrected to height

\begin{tabular}{|c|c|c|c|c|c|c|c|}
\hline & \multicolumn{3}{|c|}{ Absolute values in $\mathrm{cm}(\mathrm{SD})$} & \multicolumn{4}{|c|}{ Proportionate values in \% (SD) } \\
\hline & Cis women $(n=22)$ & Trans women $(n=22)$ & $P$-value & Normalized to & Cis women $(n=22)$ & Trans women $(n=22)$ & $P$-value \\
\hline AUX-AUX & $31.70( \pm 1.83)$ & $34.25( \pm 2.51)$ & $<0.001$ & Height & $18.6( \pm 1.24)$ & $19.0( \pm 1.43)$ & 0.254 \\
\hline $\mathrm{SN}-\mathrm{U}$ & $35.74( \pm 2.31)$ & $37.79( \pm 2.13)$ & 0.004 & Height & $20.91( \pm 1.37)$ & $20.99( \pm 1.20)$ & 0.853 \\
\hline
\end{tabular}

$A U X$-AUX axillary fold to axillary fold, $S N-U$ sternal notch to umbilicus

\section{Chest proportions}

Chest width and upper body length were both significantly larger in trans women compared to cis women $(p=<0.001$, Table 3 and Fig. 2). Although both AUX-AUX and SN-U were significantly different in absolute values, their normalized values to body height were not significantly different.

\section{Breast}

Breast width (BW) following the curvature of the breasts was similar between the groups $(p=0.909)$ (Table 4, Fig. 2). After normalization to chest width, BW was proportionately smaller in trans women $(p=0.006)$. Furthermore, the intermammary distance (IMD) was similar between cis and trans women ( $p=0.957)$, also after chest width normalization $(p=0.599)$. The absolute distances from the sternal-notch to the inframammaryfold-level (SN-IMF-level) were very similar $(p=0.988)$, but after upper body length normalization, SN-IMF-level was found to be significantly smaller in trans women than in cis women $(p=0.037)$, suggesting a shorter upper thorax and more cranial positioning of the inframammary level in relation to upper body length in trans women.

\section{Nipples}

The average areolar diameter was significantly smaller in trans women $(3.45 \pm 0.70)$ than in cis women $(5.44 \pm 1.36$,

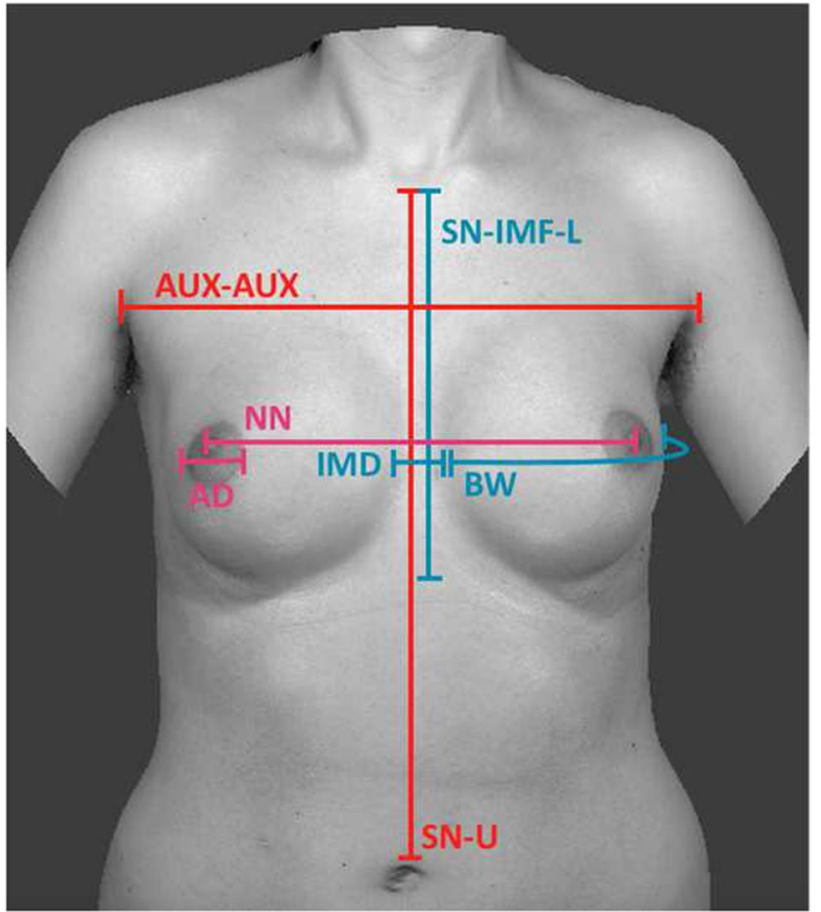

Fig. 2 Depiction of the chest (red), breast (blue), and nipple (pink) parameters in participants. AUX-AUX axillary fold to axillary fold, SN-IMF-L sternal notch to inframammary fold level, NN nipple to nipple, AD areola diameter, IMD intermammary distance, BW breast width, SN-U sternal notch to umbilicus 
Table 4 Breast dimensions in absolute and relative values corrected for chest width and upper body length

\begin{tabular}{|c|c|c|c|c|c|c|c|}
\hline & \multicolumn{3}{|c|}{ Absolute values in $\mathrm{cm}$ (SD) } & \multicolumn{4}{|c|}{ Proportionate values in \% (SD) } \\
\hline & Cis women $(n=22)$ & Trans women $(n=22)$ & $P$-value & Normalized to & Cis women $(n=22)$ & Trans women $(n=22)$ & $P$-value \\
\hline BW & $22.46( \pm 2.10)$ & $22.39( \pm 2.07)$ & 0.909 & AUX-AUX & $70.80( \pm 6.96)$ & $65.44( \pm 5.05)$ & 0.006 \\
\hline IMD & $3.83( \pm 1.44)$ & $3.85( \pm 1.86)$ & 0.957 & & $12.14( \pm 4.74)$ & $11.31( \pm 5.58)$ & 0.599 \\
\hline SN-IMF-L & $21.92( \pm 1.95)$ & $21.91( \pm 2.12)$ & 0.988 & SN-U & $61.47( \pm 5.71)$ & $57.99( \pm 4.94)$ & 0.037 \\
\hline
\end{tabular}

$B W$ breast width, $I M D$ intermammary distance, $S N-I M F-L$ sternal notch to inframammary level, $A U X$ - $A U X$ axillary fold to axillary fold, $S N-U$ sternal notch to umbilicus

The bold entities served as a marker for a measured outcome

Table 5 Nipple size and positioning in absolute and relative values normalized to breast width and upper body length and chest width

\begin{tabular}{|c|c|c|c|c|c|c|c|}
\hline & \multicolumn{3}{|c|}{ Absolute values in $\mathrm{cm}(\mathrm{SD})$} & \multicolumn{4}{|c|}{ Proportionate values in \% (SD) } \\
\hline & Cis women $(n=22)$ & Trans women $(n=22)$ & $P$-value & Normalized to & Cis women $(n=22)$ & Trans women $(n=22)$ & $P$-value \\
\hline \multicolumn{8}{|c|}{ Horizontal axis } \\
\hline NN & $21.72( \pm 2.16)$ & $25.00( \pm 2.11)$ & $<0.001$ & AUX-AUX & $68.65( \pm 6.95)$ & $73.20( \pm 6.58)$ & 0.031 \\
\hline N-LIMF & $12.08( \pm 1.24)$ & $11.11( \pm 1.49)$ & 0.026 & BW & $53.79( \pm 2.96)$ & $49.55( \pm 3.89)$ & $<0.001$ \\
\hline N-MIMF & $10.34( \pm 1.22)$ & $11.78( \pm 1.23)$ & 0.015 & & $46.20( \pm 2.96)$ & $50.45( \pm 3.89)$ & $<0.001$ \\
\hline \multicolumn{8}{|l|}{ Vertical axis } \\
\hline N-AUX & $15.56( \pm 2.45)$ & $13.95( \pm 1.91)$ & 0.019 & $\mathrm{SN}-\mathrm{U}$ & $43.63( \pm 6.77)$ & $37.00( \pm 5.28)$ & $<0.001$ \\
\hline $\mathrm{SN}-\mathrm{N}$ & $21.61( \pm 2.72)$ & $20.81( \pm 1.99)$ & 0.276 & & $60.54( \pm 7.34)$ & $55.78( \pm 5.60)$ & 0.009 \\
\hline N-IMF & $8.66( \pm 1.30)$ & $9.32( \pm 1.21)$ & 0.086 & & $24.24( \pm 3.39)$ & $24.69( \pm 3.12)$ & 0.641 \\
\hline \multicolumn{8}{|l|}{ Nipple size } \\
\hline $\mathrm{AD}$ & $5.44( \pm 1.36)$ & $3.45( \pm 0.70)$ & $<0.001$ & & & & \\
\hline
\end{tabular}

$N N$ nipple to nipple distance, $N$-LIMF nipple to lateral inframammary border, $N$ - $M I M F$ nipple to medial inframammary border, $N$ - $A U X$ nipple to axillary fold, $S N-N$ sternal notch to nipple, $N$-IMF nipple to inframammary fold, $A D$ areola diameter, $A U X$ - $A U X$ axillary fold to axillary fold, $B W$ breast width, $S N-U$ sternal notch to umbilicus

The bold entities served as a marker for a measured outcome

$p=<0.001$ ) (Table 5, Figs. 2 and 3). Furthermore, the distance between the nipples (NN) was significantly larger in trans women $(p=0.031)$. The distances from nipple to the lateral (N-LIMF) and medial (N-MIMF) border of the inframammary fold were significantly different in absolute and normalized values. N-LIMF was longer in cis women $(p=0.026)$, whereas N-MIMF was longer in trans women $(p=0.015)$. After normalization to breast width, this difference maintained a significantly larger proportioned N-LIMF in cis women $(p=<0.001)$ and a significantly larger proportioned N-MIMF in trans women $(p=<0.001)$, underlining the finding that nipples of trans women are positioned more lateral on the breast. The distances from nipple-to-IMF (N-IMF) were similar, both in absolute value $(p=0.086)$ and after normalization to upper body length $(p=0.641)$. Differently, the distance between nipple-and-axillary-fold (N-AUX) $(p=<0.019)$ was shorter in trans women, which was also seen after normalization to upper body length $(p=<0.001)$. The distance from sternal-notch-to-nipple $(\mathrm{SN}-\mathrm{N})(p=0.276)$ was fairly similar between the groups for absolute values, but after upper body length normalization,

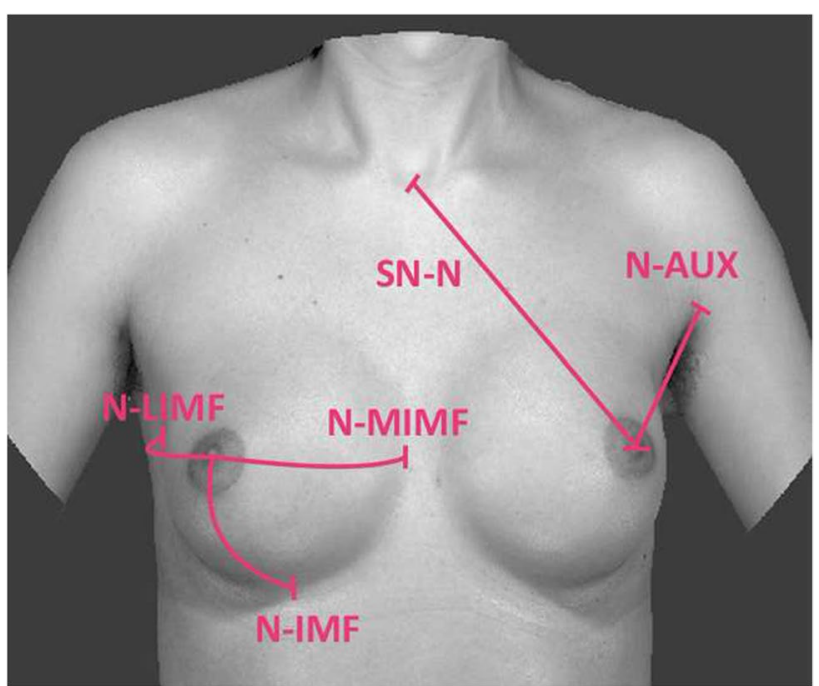

Fig. 3 Depiction of the nipple positioning measurements in participants. N-LIMF nipple to lateral inframammary border, N-MIMF nipple to medial inframammary border, N-IMF nipple to inframammary fold, SN-N sternal notch to nipple, N-AUX nipple to axillary fold 
SN-N was found to significantly shorter in trans women $(p=0.009)$. These findings suggest that the nipples are situated more latero-cranially on the augmented chest in trans women.

\section{Discussion}

The aim of this study was to establish the morphometric differences between the augmented breasts of trans and cis women. The results of this study provide insight into these differences based on gender-specific chest configurations, breast position, and nipple positioning in trans women. The chest in trans women was found to be proportionately shorter relative to upper body length, which was reflected in the breasts being positioned more cranially. Differences were also found in nipple positioning and size. Besides these distinctive features, some important similarities were also found between the groups such as nipple-to-IMF (N-IMF) distance and a similar intermammary (IMD) distance. Importantly, it remains necessary to analyze these findings not only exclusively based on their statistical significance but also in view of their clinical significance. Due to the scarcity of studies on trans breast augmentations, we sought to further substantiate the distinctive differences and establish how these might impact preoperative planning and expectation management in trans women.

The claimed dissimilarities between cis and trans women primarily focused on a wider IMD and shorter N-IMF [18-20, 25]. Our data did not support the claims that these outcomes were predestined to be present in trans women. We will discuss the outcomes of the IMD further down in the discussion, as it seems that surgical planning directly influences IMD. Moreover, it has been claimed that the distance from nipple-to-IMF was shorter both preoperatively and postoperatively [20,25]. Although an anthropometric study confirmed a relatively underdeveloped lower breast pole in trans women preoperatively, our data suggest that this shorter N-IMF is resolved after breast implants have been in situ for up to a year [25]. Another finding of this study was that the breasts were situated relatively more cranially in trans women. To achieve a more cis femalelike breast position, some have argued to actively lower the inframammary fold (IMF) [25]. Regardless of our clinical practice where we do not actively lower the IMF, our data showed similar results for N-IMF, which makes lowering the IMF a less indicated approach. The results presented in this study are therefore a direct reflection of our practice, where we prefer to allow the implants to settle. In our understanding, this approach is not considered standard of care, but for now, few scientific reports have objectified the results of lowering the IMF in trans women and therefore remains based on anecdotal evidence. In both trans and cis women, some likely adverse effects due to lowering the IMF are creating high-riding nipples and bottoming out $[16,18$, 19]. This suggests, with our approach, that the more cranial positioning of the IMF dictates a certain inevitability and necessity for this more cranial placement of the implants. A solution would be to try to lengthen the overall sternalnotch-to-IMF distance by means of implant choice or relative overexpansion of the upper breast pole. Infra-clavicular tissue expansion has already been described as a successful method to lengthen the upper breast pole in cis women [9]. Although this method of cranial tissue expansion is an established technique in two-staged breast reconstructions in cis women, this expansive and more laborious method remains a rare option in the treatment of trans women.

In another effort to overcome some of the other morphological differences, implant choice might play a more defining role in trans women. Although discussions on the aesthetic outcomes and distinguishability of implant shapes in cis women have been long and ongoing, a recent anthropometric study showed that round and anatomically shaped implants influence breast morphology differently [7, 17, $24,26]$. A cadaver study showed that anatomically shaped implants were more adept at creating a longer IMF-N, and to a lesser extent, lengthening the SN-N too [14]. Importantly, these outcomes reflected the morphology directly after implant placement and do not reflect long-term outcomes that tissue quality and implant texture might have on eventual breast shape and position. One could also argue that in time, settled smooth implants result in more lower and upper pole definition, which makes them a preferred option for trans women. While strong arguments have been made for the use of smooth, low projection round implants, no all-encompassing recommendation seems in place and the choice for implant remains subject to the surgeon's discretion [13, 18, 25].

Similarly to cis women, the most appropriate positioning of implants is generally chosen based on tissue coverage. Generally, less glandular tissue and more pronounced pectoral muscles are seen in trans women. Despite that subglandular pockets result in more prominent projection, risk of skin wrinkling and implant visibility are present. If patients have pronounced pectoral muscles such as in trans women, subpectoral placement and dual-plane placement can be less preferred due to the risk for cranial and pre-pectoral displacement respectively [30]. Subpectoral placement might, therefore, induce a more pronounced malposition due to the already more cranial position of the implant and risk for pectoral animation defects. Nevertheless, if overlaying tissue allows for it, the use of the subglandular pocket might actually be the more appropriate approach. This study also showcased that the breast width in trans women was relatively smaller in relation to chest width. Clinically, this means that the chosen implant widths in this series were relatively 
too small in comparison to chest width. The need for wider implants has been previously emphasized on by Nauta et al. [25] Choosing wider implants might be able to create medial cleavage while maintaining adequate lateral fullness, which plays into a more ideal positioning of the nipple [23].

The dissimilar position of the nipples is especially important since NAC-positioning is considered the most important landmark in breast augmentation and the biggest determinant of patient satisfaction [32]. Several aesthetic algorithms have been proposed to pinpoint the most aesthetically pleasing positioning of the nipple [3, 21, 22]. Most of these studies agree on the notion that the ideal position of the nipple is centered on the apex of the breast. This presumption poses potential issues in trans women since the more lateral positioning of the nipple dictates a more lateral placement of the implants, which might then result in a wider IMD [23]. Although brassieres and body-shaping undergarments can alter breast morphology, it should be noted that the outcomes of this study project the measurements of the naked breast. Despite having been previously stated in the literature, our data did not support the claims that a wider IMD was predestined to be present in trans women [18-20]. In our experience, most trans women actually strongly favored static cleavage formation, and as a result, opted for a more medial placement of the implants, and therefore narrowing the IMD, but also placing the nipples more laterally on the breasts. As previously mentioned, opting for wider base implants could allow for a satisfactory cleavage while also maintaining lateral fullness. However, our clinical inclination to prioritize static cleavage formation is reflected in the outcomes of this study. This plays into the presumption that the more ideal placement of the nipple is less of a priority for trans women than having a more prominent cleavage.

Once again, it is necessary to analyze these findings not only exclusively based on their statistical significance but also in view of their clinical significance. Because of the apparent differences, expectation management should play an even more prominent role in the preoperative consultation of trans women. In this study, most trans women favored cleavage formation and as a result did not mind the relative lateral positioning of the nipples, whereas other trans women might prefer a more cis female-like breast configuration with a more appropriate nipple positioning in relation to the breast itself. During the consultation, it is also important to mention that the nipples will not exponentially grow and might look even smaller when larger implants are chosen.

Limitations of this study include the relatively small sample size, which did not allow for subgroup analysis on implant shape, placement, or size. Furthermore, we were unable to provide more detailed accounts on preoperative breast and chest images and on data such as implant width and texture. Additionally, there are also some limitations to the 3-D-assisted measuring method. Although it has a good utility and reproducibility, measurements following the skin curvature such as BW and N-IMF are known to be less accurate due to the possibility of obscured landmarks. For this reason, we chose to only include women with minor to moderate breast ptosis, which allowed for a clearly defined and visible IMF [28]. Some differences could also be due to chance because of multiple testing and ideally the patients would be case-controlled based on age, weight, and implant characteristics. Furthermore, the time between augmentation and imaging was significantly different. Therefore, morphological changes due to aging have not been accounted for. Fortunately, morphological changes up to 10 years after augmentation remain small and validates the use of this comparative cohort of cis women [29]. Despite these limitations, this study found highly distinctive characteristics in breast anthropometry between trans and cis women, and is the first study to have compared these outcomes in such detail. Future studies can help further establish the relationship between morphological differences, patient satisfaction, and expectations in trans women.

This study identified distinct differences between augmented breasts of cis and trans women. Taking into account the specific consideration in the preoperative planning of trans women, we strongly emphasize the necessity of proper counseling and shared decision-making. Within gender-affirming surgery, this approach to the individualized trajectory has become an increasingly important aspect of the surgical treatment of gender dysphoria. By pointing out the inherent differences, it seems that implants should more so be placed not according to anatomy, but rather by choice and considerations of the patient. Besides emphasizing the necessity for these specific considerations for the treatment of trans women, these new objective insights could form the basis for future studies on surgical techniques, patient education, and implant properties such as texture and shape. Furthermore, these insights emphasize the necessity of individualized shared decision-making and proper expectation management.

\section{Declarations}

All authors have seen and agree on the submitted version. We declare that the material is original and has not been published elsewhere.

Ethical approval All procedures performed in studies involving human participants were in accordance with the Declaration of Helsinki and guidelines for Good Practice. The protocol was approved by the institutional ethics review board of the Amsterdam UMC (2019.011).

Conflict of interest Floyd Wilhelmus Timmermans, Sterre Elisabeth Mokken, Brian Scheffers, Mark-Bram Bouman, Margriet Mullender, and Tim van de Grift declare no competing interests. 
Informed consent Informed consent was obtained from all individual participants included in the study.

Patient consent Patients signed informed consent regarding publishing their data and photographs.

Open Access This article is licensed under a Creative Commons Attribution 4.0 International License, which permits use, sharing, adaptation, distribution and reproduction in any medium or format, as long as you give appropriate credit to the original author(s) and the source, provide a link to the Creative Commons licence, and indicate if changes were made. The images or other third party material in this article are included in the article's Creative Commons licence, unless indicated otherwise in a credit line to the material. If material is not included in the article's Creative Commons licence and your intended use is not permitted by statutory regulation or exceeds the permitted use, you will need to obtain permission directly from the copyright holder. To view a copy of this licence, visit http://creativecommons.org/licenses/by/4.0/.

\section{References}

1. Agarwal CA, Wall VT, Mehta ST, Donato DP, Walzer NK (2017) Creation of an aesthetic male nipple areolar complex in femaleto-male transgender chest reconstruction. Aesthetic Plast Surg 41(6):1305-1310. Retrieved from https://www.ncbi.nlm.nih.gov/ pubmed/28698936. https://doi.org/10.1007/s00266-017-0935-7

2. Al-Tamimi M, Pigot GL, Elfering L, Ozer M, de Haseth K, van de Grift TC et al (2020) Genital gender-affirming surgery in transgender men in The Netherlands from 1989 to 2018: the evolution of surgical care. Plast Reconstr Surg 145(1):153e-161e. Retrieved from https://www.ncbi.nlm.nih.gov/pubmed/31881624. https://doi.org/10.1097/PRS.0000000000006385

3. Atiye B, Chahine F (2018) Metrics of the aesthetically perfect breast. Aesthetic Plast Surg 42(5):1187-1194. Retrieved from https://www.ncbi.nlm.nih.gov/pubmed/30006829. https://doi.org/ 10.1007/s00266-018-1154-6

4. Beckenstein MS, Windle BH, Stroup RT Jr (1996) Anatomical parameters for nipple position and areolar diameter in males. Ann Plast Surg 36(1):33-36. Retrieved from https://www.ncbi.nlm.nih. gov/pubmed/8722981. https://doi.org/10.1097/00000637-19960 1000-00007

5. Beer GM, Budi S, Seifert B, Morgenthaler W, Infanger M, Meyer VE (2001) Configuration and localization of the nipple-areola complex in men. Plast Reconstr Surg 108(7):1947-1952; discussion 1953. Retrieved from https://www.ncbi.nlm.nih.gov/pubmed/ 11743381. https://doi.org/10.1097/00006534-200112000-00015

6. Berli JU, Knudson G, Fraser L, Tangpricha V, Ettner R, Ettner FM et al (2017) What surgeons need to know about gender confirmation surgery when providing care for transgender individuals: a review. JAMA Surg 152(4):394-400. https://doi.org/10.1001/ jamasurg.2016.5549

7. Cheng F, Cen Y, Liu C, Liu R, Pan C, Dai S (2019) Round versus anatomical implants in primary cosmetic breast augmentation: a meta-analysis and systematic review. Plast Reconstr Surg 143(3):711-721. Retrieved from https://www.ncbi.nlm.nih. gov/pubmed/30601325. https://doi.org/10.1097/PRS.0000000000 005371

8. Coleman E, Bockting W, Botzer M, Cohen-Kettenis P, DeCuypere G, Feldman J et al (2012) Standards of care for the health of transsexual, transgender, and gender-nonconforming people, version 7. International Journal of Transgenderism 13(4):165-232.
Retrieved from https://doi.org/10.1080/15532739.2011.700873. https://doi.org/10.1080/15532739.2011.700873

9. Colwell AS, May JW Jr, Slavin SA (2007) Lowering the postoperative high-riding nipple. Plast Reconstr Surg 120(3):596-599. Retrieved from https://www.ncbi.nlm.nih.gov/pubmed/17700109. https://doi.org/10.1097/01.prs.0000270283.64971.dd

10. de Blok CJM, Klaver M, Wiepjes CM, Nota NM, Heijboer AC, Fisher AD et al (2018) Breast development in transwomen after 1 year of cross-sex hormone therapy: results of a prospective multicenter study. J Clin Endocrinol Metab 103(2):532-538. Retrieved from. https://doi.org/10.1210/jc.2017-01927

11. de Blok CJM, Staphorsius AS, Wiepjes CM, Smit JM, Nanayakkara PWB, den Heijer M (2019) Frequency, determinants, and satisfaction of breast augmentation in trans women receiving hormone treatment. J Sex Med. Retrieved from https://www.ncbi.nlm. nih.gov/pubmed/31806494. https://doi.org/10.1016/j.jsxm.2019. 10.021

12. Deutsch MB, Radix A, Wesp L (2017) Breast cancer screening, management, and a review of case study literature in transgender populations. Semin Reprod Med 35(5):434-441. Retrieved from https://www.ncbi.nlm.nih.gov/pubmed/29073682. https://doi.org/ 10.1055/s-0037-1606103

13. Fakin, RM, Zimmermann S, Kaye K, Lunger L, Weinforth G, Giovanoli P (2019) Long-term outcomes in breast augmentation in trans-women: a 20-year experience. Aesthet Surg J 39(4):381390. Retrieved from https://academic.oup.com/asj/article-abstr act/39/4/381/5036559?redirectedFrom=fulltext. https://doi.org/ 10.1093/asj/sjy143

14. Forte AJ, Barbosa MP, Persing JA, Alonso N, Berlin N, Broer N et al (2015) Cadaveric study of breast measurements during augmentation with implants. Plast Reconstr Surg 135(4):699e-710e. Retrieved from https://www.ncbi.nlm.nih.gov/pubmed/25811582. https://doi.org/10.1097/PRS.0000000000001060

15. Hage JJ, van Kesteren PJ (1995) Chest-wall contouring in femaleto-male transsexuals: basic considerations and review of the literature. Plast Reconstr Surg 96(2):386-391. Retrieved from https:// www.ncbi.nlm.nih.gov/pubmed/7624412. https://doi.org/10.1097/ 00006534-199508000-00019

16. Hidalgo DA (2000) Breast augmentation: choosing the optimal incision, implant, and pocket plane. Plast Reconstr Surg 105(6):2202-2216; discussion 2217-2208. Retrieved from https:// www.ncbi.nlm.nih.gov/pubmed/10839422. https://doi.org/10. 1097/00006534-200005000-00047

17. Hidalgo DA, Sinno S (2016) Current trends and controversies in breast augmentation. Plast Reconstr Surg 137(4):1142-1150. Retrieved from https://www.ncbi.nlm.nih.gov/pubmed/27018669. https://doi.org/10.1097/01.prs.0000481110.31939.e4

18. Kanhai RC, Hage JJ, Asscheman H, Mulder JW (1999) Augmentation mammaplasty in male-to-female transsexuals. Plast Reconstr Surg 104(2):542-549, discussion 550-541. https://doi.org/10. 1097/00006534-199908000-00039

19. Kanhai RC, Hage JJ, Karim RB, Mulder JW (1999) Exceptional presenting conditions and outcome of augmentation mammaplasty in male-to-female transsexuals. Ann Plast Surg 43(5):476-483

20. Laub DR (1999) Discussion: augmentation mammaplasty in male-to-female transsexuals. Plast Reconstr Surg 104(2):550-551. Retrieved from https://journals.lww.com/plasreconsurg/Fulltext/ 1999/08000/Augmentation_Mammaplasty_in_Male_to_Female. 41.aspx

21. Mallucci P, Branford OA (2014) Population analysis of the perfect breast: a morphometric analysis. Plast Reconstr Surg 134(3):436447. Retrieved from https://www.ncbi.nlm.nih.gov/pubmed/25158 703. https://doi.org/10.1097/PRS.0000000000000485

22. Mallucci P, Branford OA (2016) Design for natural breast augmentation: the ICE principle. Plast Reconstr Surg 137(6):1728-1737. 
Retrieved from https://www.ncbi.nlm.nih.gov/pubmed/27219229. https://doi.org/10.1097/PRS.0000000000002230

23. Miller TJ, Wilson SC, Massie JP, Morrison SD, Satterwhite $\mathrm{T}$ (2019) Breast augmentation in male-to-female transgender patients: technical considerations and outcomes. JPRAS Open 21:63-74. Retrieved from https://www.ncbi.nlm.nih.gov/pubmed/ 32158888. https://doi.org/10.1016/j.jpra.2019.03.003

24. Miller TJ, Wilson SC, Massie JP, Morrison SD, Satterwhite $T$ (2019) Breast augmentation in male-to-female transgender patients: technical considerations and outcomes. JPRAS Open 21:63-74. Retrieved from https://www.ncbi.nlm.nih.gov/pubmed/ 32158888. https://doi.org/10.1016/j.jpra.2019.03.003

25. Nauta AC, Baltrusch KM, Heston AL, Narayan SK, Gunther S, Esmonde NO et al (2019) Differences in chest measurements between the cis-female and trans-female chest exposed to estrogen and its implications for breast augmentation. Plast Reconstr Surg Glob Open 7(3):e2167. Retrieved from https://www.ncbi.nlm.nih. gov/pmc/articles/PMC6467617/pdf/gox-7-e2167.pdf. https://doi. org/10.1097/gox.0000000000002167

26. Rocco N, Rispoli C, Moja L, Amato B, Iannone L, Testa S et al (2016) Different types of implants for reconstructive breast surgery. Cochrane Database Syst Rev (5):CD010895. Retrieved from https://www.ncbi.nlm.nih.gov/pubmed/27182693. https://doi.org/ 10.1002/14651858.CD010895.pub2

27. Miller TJ, Wilson SC, Massie JP, Morrison SD, Satterwhite $\mathrm{T}$ (2019) Breast augmentation in male-to-female transgender patients: technical considerations and outcomes. JPRAS Open 21:63-74. Retrieved from https://www.ncbi.nlm.nih.gov/pubmed/ 32158888. https://doi.org/10.1016/j.jpra.2019.03.003
28. Steen K, Isaac KV, Murphy BD, Beber B, Brown M (2018) Threedimensional imaging and breast measurements: how predictable are we? Aesthet Surg J 38(6):616-622. https://doi.org/10.1093/ asj/sjx 232

29. Swanson E (2018) Photometric evaluation of long-term changes in breast shape after breast augmentation and vertical mammaplasty. Plast Reconstr Surg Glob Open 6(6):e1844. Retrieved from https://www.ncbi.nlm.nih.gov/pubmed/30276063. https://doi.org/ 10.1097/GOX.0000000000001844

30. Tebbetts JB (2006) Dual plane breast augmentation: optimizing implant-soft-tissue relationships in a wide range of breast types. Plast Reconstr Surg 118(7 Suppl):81S-98S; discussion 99S-102S. Retrieved from https://www.ncbi.nlm.nih.gov/pubmed/17099485. https://doi.org/10.1097/00006534-200612001-00012

31. Wiepjes CM, Nota NM, de Blok CJM, Klaver M, de Vries ALC, Wensing-Kruger SA et al (2018) The Amsterdam cohort of gender dysphoria study (1972-2015): trends in prevalence, treatment, and regrets. J Sex Med 15(4):582-590. Retrieved from https://www. ncbi.nlm.nih.gov/pubmed/29463477. https://doi.org/10.1016/j. jsxm.2018.01.016

32. Youn ES (2006) Importance of the new position of the nippleareola complex in breast augmentation surgery. Plast Reconstr Surg 118(7 Suppl):18S-31S; discussion 32S-34S. Retrieved from https://www.ncbi.nlm.nih.gov/pubmed/17099480. https://doi.org/ 10.1097/01.prs.0000246235.00439.3d

Publisher's note Springer Nature remains neutral with regard to jurisdictional claims in published maps and institutional affiliations. 